\title{
14
}

\section{A Process Model for Sustainable Business Model Innovation}

In this chapter, we take one step further toward exploring how to build on the insights from the RESTART framework when attempting to conduct a sustainable business model innovation in practice. Like any innovation process, this will require considerable change in the organization, which implies that there are considerable management and leadership challenges involved. It requires a willingness to enter "the dark room of innovation", and an ability to ask the right questions once you are inside the dark room, which may allow you to find the light switch. For this purpose, we have developed "The Business Model RESTARTer", a process model that can serve as inspiration and guidance in such a change process.

We have argued that in the future, companies will have to redesign their business models more often. This book's point of departure was that three major trends drive this need for continuous business model innovation: first, the comprehensive sustainability problem, which is both a threat and an opportunity for companies; second, the technological opportunity space related to digitalization and the fourth industrial revolution, which renders old business models obsolete and opens up for completely novel business models, and third, ongoing changes in 

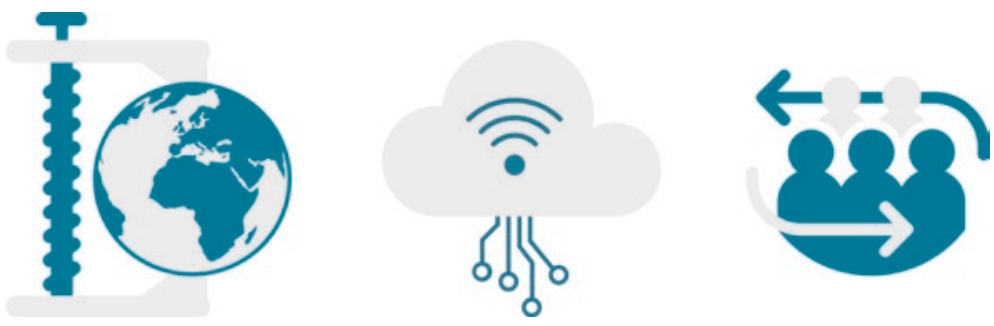

Fig. 14.1 Three trends driving the development of new business models

consumer preferences, lifestyles and consumption patterns that make new types of value creation both possible and necessary (Fig. 14.1).

The big question is how companies should go about designing new business models that take all of these three trends into consideration. As researchers, when we work with companies, one of our aims is to enable the managers from the company to develop questions that can be tested empirically and form the basis for simple pilot tests, A/B tests or experiments. Our collaboration with companies is part of the background that gave the spark to develop the RESTART framework outlined in Part II. Working with managers in innovation processes has also led us to believe that managers need a knowledge-based model to guide their innovation processes. The Business Model RESTARTer aims to be such a tool. This process model gives "a view from 30,000 feet" and intends to help managers ask the right questions at the right time and thus get closer to the light switch in the dark room of innovation.

We conceive of The Business Model RESTARTer as a reiterative process model in which we divide the sustainable business model innovation process into four phases (Fig. 14.2):

1. Recognize your business model—understanding the status quo and identifying the need for change

2. Rethink your business model-identifying opportunities, threats and possibilities for an improved business model

3. Reinvent your business model-hypothesizing, testing and deciding on a new business model

4. Reorganize your business model_-implementing the new business model

The business model is the focal point of the RESTART framework developed in Part II, and therefore we have placed the business model in 


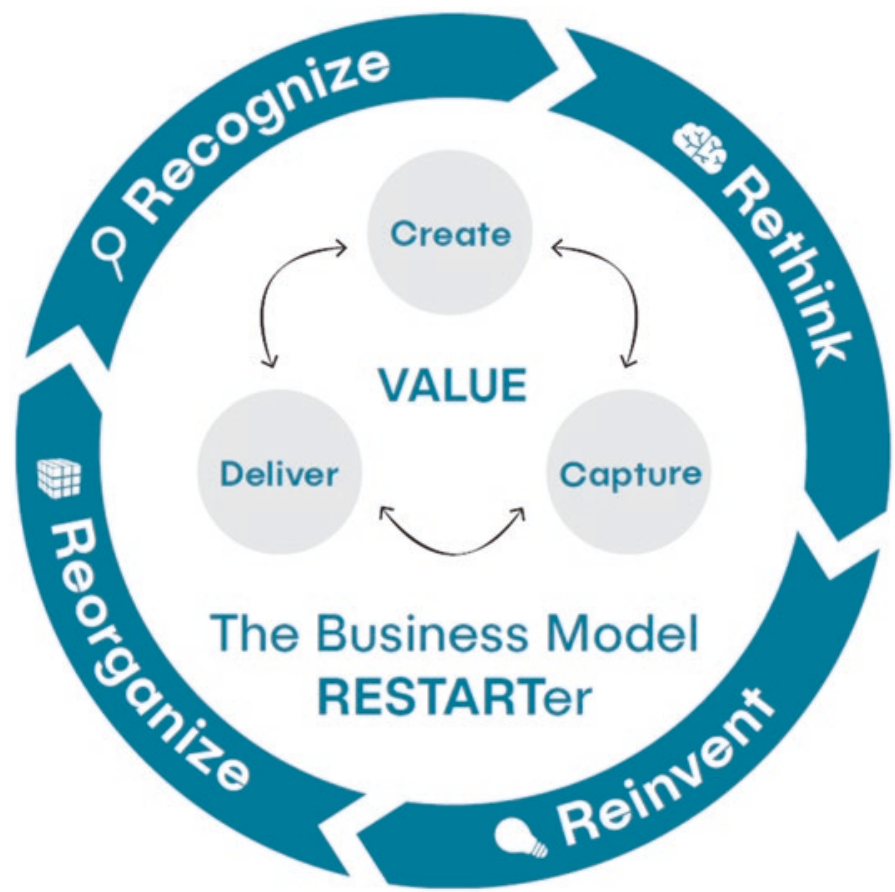

Fig. 14.2 The business model RESTARTer for sustainable business model innovation

the middle of the model. This is illustrated by the three gray circles that represent how companies create, deliver and capture value. The four phases, recognizing, rethinking, reinventing and reorganizing the business model, are illustrated in the quadripartite and cyclical arrow surrounding the business model. All four phases are related to the business model, and as we will discuss below, elements from the RESTART framework serve as important building blocks in the whole process from recognizing the current business model to reorganizing in order to facilitate the new one.

We propose that any innovation process needs to start with a recognition of the current business model and an identification of its shortcomings - its negative and positive externalities. The next phase is to rethink the business model. This includes an examination of the threats from novel business models from new and existing competitors and a thorough exploration of the current business model's failure to exploit the opportu- 
Table 14.1 Questions to guide the four phases of the sustainable business model innovation process

(1) Recognize your business model

(2) Rethink your business model

(3) Reinvent your business model

(4) Reorganize your business model
- Who are your target customers, what problems do they have, what products and services do you offer them and what is your value proposition to these customers?

- How do you deliver value, that is, what are the key resources, activities and partners that allow you to deliver on your value proposition reliably over time?

- How do you capture value, that is, what are your most important sources for revenue and cost?

- What are your current ambitions? And what scope and time horizon do you have for growth?

- What are the main negative and positive externalities of your business model?

- Which jobs do customers really want to have done?

- Which technological and societal trends and drivers influence your business model?

- Who are the main players in your industry?

- How can elements from the RESTART framework be an inspiration for sustainable business model innovation?

- Is there a platform for change and a culture for a RESTART in your organization? If not: What are the main obstacles and how can you overcome them?

- What are your new ambitions? And what time horizons and scope for growth do you have now?

- Who should your customers be?

- What should your new value proposition(s) be, and how can value be delivered and captured in new ways?

- What needs to be true for the new business model(s) to go to market?

- How can you test and experiment with new business models?

- Is there a strong relationship between the new ways of creating, delivering and capturing value in your business model?

- Are you organized to leverage your resources and facilitate value-creating activities?

- Are you counting, incentivizing and communicating the things that really matter?

- How are you preparing your business for a new RESTART? 
nity space related to changes in markets, technologies and consumer preferences. These two first phases, recognize and rethink, can be understood as a problem formulation, while the purpose of the two next phases, reinvent and reorganize, is to develop and test new solutions and to integrate them in a new business model.

We will dig deeper into all of these four phases below. Before we do so, we outline some questions in Table 14.1 that we have found useful to ask in the different phases of such an innovation process.

\subsection{A Closer Look at the Four Phases of the Sustainable Business Model Innovation Process}

The Business Model RESTARTer is inspired by the business model innovation literature (e.g., Osterwalder and Pigneur 2010; Kaplan 2012; Gassmann et al. 2014; Morris et al. 2005; see also Foss and Saebi 2017; Zott et al. 2011) and the organizational change literature (in particular, Lewin 1947). Lewin's well-known model suggests that change processes have three phases, popularly summarized as unfreeze-change-freeze. By unfreeze, Lewin refers to making the organization ready to change, while change refers to the actual implementation of novel solutions and freeze (or refreeze) is ultimately about making the new features of the organization stick. In order to make impactful and lasting change, all three are necessary.

The first phase of a RESTART is to recognize the current business model, which is illustrated at the top left of Fig. 14.2. Such a recognition involves understanding how the company creates, delivers and captures value today. Moreover, this implicates examining the negative and positive externalities of the current business model. We have discussed these shadowy and sunny sides of the business model in the first part of the book, but it has also been a returning theme throughout the book - not at least in the discussion of what constitutes material sustainability concerns. Many of the managers we work with have an implicit understanding of their business models, and when we use this framework we put quite a lot 
of effort into making the managers examine their current business model(s) explicitly. When we work with entrepreneurs, who might only have an idea about a product or a service, we make them spend time on recognizing the existing business models in the market they want to enter.

The second phase is to rethink the business model, which is illustrated at the top right of Fig. 14.2. As noted above, this is still a part of what Lewin denotes the change, or unfreeze, process. One thing is to know the company's business model, another thing altogether is to analyze the company's ecosystem, including important technological and societal trends and drivers, stakeholders, competitors and other players. In addition, companies must assess the internal factors of relevance for the business model innovation process. In this stage, it is important to assess if there is a culture for a RESTART in the company and if there is a "burning platform" shared by the top management team and the board. If this is not the case, actions should be undertaken to ensure that important stakeholders are onboard and that there is a common understanding of problems that need to be solved with the current business model.

The third phase of the innovation process is to reinvent the business model, illustrated at the bottom right of Fig. 14.2. Albert Einstein supposedly said that if he had only one hour to save the world, he would spend 55 minutes defining the problem and only five minutes finding the solution. In other words, he would trust that the solution would come to him if he only understood what the problem really was. Thus, we can think of the two first phases as problem formulation and the third phase as finding the solution(s) to the problem. We often experience that truly novel and innovative solutions tend to emerge as a result of thorough problem formulation and that the questions that arise in phases one and two make managers view their organizations with fresh eyes.

In the reinvent phase, several elements from the RESTART framework are relevant, regarding the understanding of new business models (redesign), testing and piloting (experimentation), as well as specific ideas for new business models informed by the perspectives on service-logic, circular business models and alliances. Generally, the aim in this phase is to develop and test new ways of creating, delivering and capturing value, while at the same time reducing the shadowy sides and increasing the 
sunny sides of the business model. As we have discussed in this book, how this is done depends on, for instance, what industry the company is in, if it is possible to digitize and virtualize its products, if there is a demand from customers for more sustainable products and services, and so on.

One way of working with rethinking and reinventing the business model is to use the insights from the UN Global Compact, as we discussed using, for instance, the Aker BioMarine case in Part II. The UN Global Compact (UNGC) defines ten principles that can be understood as the minimal responsibilities of companies, that is, the fundamental values that business needs to integrate in their strategies and operations to ensure that they minimize the shadowy sides of their companies in the areas of human rights, labor, the environment and anti-corruption. The UN SDGs, on the other hand, can be used to explore the sustainability opportunities and the sunny sides of the business model, that is, "the upside" of sustainability. One cannot expect that one company can solve all of the 17 goals. However, after an assessment of the current business model and its negative and positive externalities, managers can use one or more of the SDGs as inspiration to find new ways of creating, delivering and capturing value. As shown in the case of Aker BioMarine, the company actively used the SDGs to prioritize which societal and environmental problems it could contribute to solving, given the nature of its business model. Similarly, other companies can examine their business models, their shadowy sides using the UNGC principles, and then explore opportunities to shed light by building on one or more relevant SDGs.

After new ideas are piloted and tested, and choices made regarding a new business model, the fourth phase is to reorganize the business model. Lewin called this step freeze or refreeze, and it involves making changes related to organizational design, leadership, management control and governance systems. The purpose is to rebuild the organization in a way that facilitates and supports the new business model and to make sure that the changes made are lasting and that the company does not revert to business as usual as soon as the enthusiasm for novelty fades. The insights from the three-dimensionality chapter in the second part of the book are particularly important and applicable in this phase. 


\subsection{Why the Business Model RESTARTer?}

You might ask why we need a process model in addition to the RESTART framework. In the second part of the book, we discussed the seven components in RESTART. It is, however, not necessarily fruitful to follow R-E-S-T-A-R-T to the letter, starting the process with redesign and ending with three-dimensionality. It goes without saying that the first step of a sustainable business model innovation is not to redesign the business model. Such a redesign should definitely be the aim of the process, but successful redesign requires using input from the other six components in RESTART in order to understand how to create, deliver and capture value in new ways.

One could even argue that a better way to achieve a RESTART is to reverse the sequence of the letters, that is, perform a TRATSER rather than a RESTART. Following TRATSER to the letter would involve beginning the process with taking three-dimensionality seriously in order to define the new objectives and goals of the company, considering the financial, environmental and social dimensions. In turn, the process could continue with aiming for the right results by assessing stakeholders and materiality and thereby identifying how to become both sustainable and profitable by addressing mechanisms for increasing revenues and reputation and/or reducing costs and risk. Next, the analyses would continue based on insights related to how alliances, perspectives from the circular economy and service-logic could inform the prototype of a new business model. This new business model could be tested using insights on experimentation. Finally, based on these analyses, the company would be ready for a redesign of its business model.

\subsection{Starting the RESTART}

Our experience is that wise managers are able to jump back and forth in business model innovation processes and can thus use the different parts of the framework at different times depending on what kinds of problems they need to understand and solve. Companies will typically have different starting points for a RESTART, and as we discussed in the sec- 
ond part of the book, there are different pull and push factors that can drive a sustainable business model innovation process (see Table 10.1 in Chap. 10 on Results rather than indulgences).

One starting point for a company can be that it needs to become more circular due to new regulations or motivated by the possibility to reduce cost. If so, the discussions and analysis often start with understanding what a circular business model is, what embracing such a model would imply for the company, with which partners the company would need to collaborate or how it can use insights from service-logic to turn its products into services. Another starting point can be that the company's board or its investors demand materiality assessments, risk assessments or new KPIs that reflect the sustainability performance of the company. Increasingly, we see that such pressures meet managers in companies across all industries. The outcome of a materiality assessment might be that the managers understand that they need to redesign the company's business model to address stakeholder expectations, while new KPIs might similarly lead to a redesign of how the company delivers and captures value.

Other starting points for a RESTART can be new technologies, competition from new players in the market, new regulations, price increases or increased supply risks for important resources, and so on. Whatever the motivation for a sustainable business model might be, we propose that managers need to understand their current business model and the threats and opportunities related to it, which is the point of departure for how it can be changed in ways that improve both sustainability performance and business performance more broadly. The Business Model RESTARTer can be used as a way to structure such an innovation process, asking the right kinds of questions in pursuit of the right answers.

Visit our website www.JorgensenPedersen.no for more tips, videos and materials to use-either as a facilitator of a RESTART in your own company, as a consultant for others, as an entrepreneur mapping out existing business models in the market or a fellow researcher like us who needs a toolbox for working with companies in order to carve out researchable hypotheses that can be tested empirically. We will discuss such research projects in the following chapters, starting with a general discussion of avenues for future research, before we dig deeper into two business cases based on the RESTART framework. 


\section{References}

Foss, N. J., \& Saebi, T. (2017). Fifteen years of research on business model innovation: How far have we come, and where should we go? Journal of Management, 43(1), 200-227.

Gassmann, O., Frankenberger, K., \& Csik, M. (2014). The business model navigator: 55 models that will revolutionise your business. Harlow, UK: Pearson UK.

Kaplan, S. (2012). The business model innovation factory: How to stay relevant when the world is changing. London: John Wiley \& Sons.

Lewin, K. (1947). Group decision and social change. Readings in Social Psychology, 3, 197-211.

Morris, M., Schindehutte, M., \& Allen, J. (2005). The entrepreneur's business model: Toward a unified perspective. Journal of Business Research, 58(6), 726-735.

Osterwalder, A., \& Pigneur, Y. (2010). Business model generation: A handbook for visionaries, game changers, and challengers. London: John Wiley \& Sons.

Zott, C., Amit, R., \& Massa, L. (2011). The business model: Recent developments and future research. Journal of Management, 37(4), 1019-1042.

Open Access This chapter is licensed under the terms of the Creative Commons Attribution-NonCommercial-NoDerivatives 4.0 International License (http:// creativecommons.org/licenses/by-nc-nd/4.0/), which permits any noncommercial use, sharing, distribution and reproduction in any medium or format, as long as you give appropriate credit to the original author(s) and the source, provide a link to the Creative Commons license and indicate if you modified the licensed material. You do not have permission under this license to share adapted material derived from this book or parts of it.

The images or other third party material in this chapter are included in the chapter's Creative Commons license, unless indicated otherwise in a credit line to the material. If material is not included in the chapter's Creative Commons license and your intended use is not permitted by statutory regulation or exceeds the permitted use, you will need to obtain permission directly from the copyright holder.

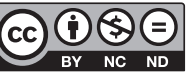

